\title{
Resenha do livro: $O$ esporte nas eleições 2018: candidaturas à presidência da república e aos governos dos estados
}

\section{RESUMO}

Livro publicado em 2019, produzido por um grupo de pesquisadores membros de três diferentes instituições: Universidade Estadual de Maringá (UEM), da Universidade Estadual do Sudoeste da Bahia (UESB) e da Secretaria Estadual Paraná do Colégio Brasileiro de Ciências do Esporte (CBCE-PR). A obra objetivou evidenciar o local do esporte nas propostas do Poder Executivo ao identificá-lo nos planos de governo das candidaturas a presidência da República e a governo dos estados brasileiros e do Distrito Federal. A amostra foi composta por 203 candidaturas, distribuídas pelas cinco regiões geográficas e União. Os autores do livro optaram por não realizar uma análise sobre as propostas, buscando com isso manter um caráter neutro, sem qualquer tipo de posicionamento político-partidário ou juízo de valor.

PALAVRAS-CHAVE: Políticas públicas de esporte; Planos de governo; Eleições 2018

\section{Marcus Peixoto de Oliveira}

Mestre em Estudos do Lazer Universidade Federal de Minas Gerais, Programa de Pós-Graduação Interdisciplinar

em Estudos do Lazer, Belo Horizonte, Brasil po.marcus@gmail.com - $\underline{\text { https://orcid.org/0000-0002-8632-2961 }}$

Emerson Bevilaqua Garcia Especialista em Gestão Pública do Esporte Universidade Estadual de Ponta Grossa,

Ponta Grossa, Brasil garciabevilaqua@gmail.com - $\underline{\text { https://orcid.org/0000-0003-3620-0031 }}$ 


\title{
Book review: Sport in the 2018 elections: candidates for the presidency of the republic and the
} governments of the states

\begin{abstract}
Book published in 2019, produced by a group of researchers members of three different institutions: State University of Maringá (UEM), the State University of Southwest Bahia (UESB) and the Paraná State Secretariat of the Brazilian College of Sport Sciences (CBCE- PR). The work aimed to highlight the location of the sport in the Executive Power's proposals by identifying it in the government plans of the candidacies for the presidency of the Republic and the government of the Brazilian states and the Federal District. The sample consisted of 203 candidacies, distributed among the five geographic regions and the Union. The authors of the book chose not to carry out an analysis of the proposals, seeking to maintain a neutral character, without any kind of political-partisan position or value judgment.
\end{abstract}

KEYWORDS: Public sport policies; Government plans; Elections 2018

Reseña del libro: El deporte en las elecciones de 2018: candidatos a la presidencia de la república y gobiernos estatales

\section{RESUMEN}

Libro publicado en 2019, elaborado por un grupo de investigadores miembros de tres instituciones diferentes: Universidad Estatal de Maringá (UEM), Universidad Estatal del Sudoeste de Bahía (UESB) y Secretaría de Estado de Paraná de la Facultad Brasileña de Ciencias del Deporte (CBCEPR). El trabajo tuvo como objetivo resaltar la ubicación del deporte en las propuestas del Poder Ejecutivo identificándolo en los planes de gobierno de las candidaturas a la presidencia de la República y el gobierno de los estados brasileños y del Distrito Federal. La muestra estuvo conformada por 203 candidaturas, distribuidas entre las cinco regiones geográficas y la Unión. Los autores del libro optaron por no realizar un análisis de las propuestas, buscando mantener un carácter neutral, sin ningún tipo de posición político-partidista o juicio de valor.

PALABRAS-CLAVE: Políticas públicas deportivas; Planes gubernamentales; Elecciones 2018 
Como forma de organização, e melhor entendimento por parte do leitor, dividimos esta resenha em dois momentos. No primeiro, apresentaremos os autores organizadores da obra, os grupos de pesquisa que compuseram a equipe de investigação, assim como o material exposto nos respectivos capítulos. O segundo servirá para externarmos nossas impressões a respeito do livro, pontuando, de forma crítica, os méritos do material, além de outras possibilidades analíticas, que poderiam ter recebido maior atenção.

\section{APRESENTAÇÃO DA OBRA}

O livro intitulado "O esporte nas eleições 2018: candidaturas à presidência da república e aos governos dos estados" foi organizado por Felipe Canan, Temístocles Damasceno Silva e Fernando Augusto Starepravo, e publicado em 2019 pela Universidade Estadual do Oeste do Paraná (UNIOESTE). A produção contou com pesquisadores membros do Grupo de Estudos e Pesquisa em Políticas Públicas de Esporte e Lazer (GEPPOL) da Universidade Estadual de Maringá (UEM), do Centro de Estudos em Gestão do Esporte e Lazer (CEGEL) da Universidade Estadual do Sudoeste da Bahia (UESB) e da Secretaria Estadual Paraná do Colégio Brasileiro de Ciências do Esporte (CBCEPR).

Ao todo, a obra conta com quatro capítulos, sendo os dois primeiros, Introdução e Procedimentos Metodológicos de autoria de Felipe Canan. Em seguida, no Capítulo 3, João Paulo Melleiro Malagutti e Canan apresentam dados referentes aos candidatos à Presidência da República. E por fim, o Capítulo 4 foi dividido entre cinco pesquisadores, no qual cada um ficou responsável por abordar uma região geográfica do país e seus respectivos estados. Deste modo: Neidiana Braga da Silva Souza investigou as propostas ao cargo de Governador dos três estados do Centro-Oeste e do Distrito Federal; Temístocles Damasceno Silva foi responsável pelos nove estados do Nordeste; Jeferson Roberto Rojo investigou as propostas dos sete estados da Região Norte; Pedro Henrique Iglesiaz Menegaldo abordou todos os quatro estados do Sudeste; e Felipe Canan participa novamente, desta vez investigando as propostas da Região Sul.

Não há uma preocupação no livro em fazer uma apresentação inicial dos organizadores, tampouco um prefácio da obra realizada. Contudo, ao final, há uma seção com breve apresentação dos Grupos de Pesquisa que apoiaram o trabalho, assim como dos autores que participaram, e suas respectivas titulações acadêmicas.

Na Introdução, Canan (2019) procura contextualizar o leitor a respeito da relação Estadoesporte no Brasil, indicando que há uma participação diversificada de agentes no campo das políticas públicas de esporte. O autor afirma existir uma aproximação histórica da Administração Pública com 
a manifestação esportiva de rendimento, mesmo não sendo fruto de uma política de Estado para o setor.

Canan argumenta que a falta de um sistema estatal, coordenado por um poder central, deixa o esporte refém da ação de grupos de interesse e do perfil político-ideológico dos governantes. Logo, percebe-se um afastamento de outras possibilidades de práticas e manifestações esportivas na agenda política. "O esporte enquanto política social, nessa esteira é relegado a um segundo plano" (CANAN, 2019, p. 5).

Ainda na Introdução, o autor ressalta o pequeno destaque dado às questões ligadas ao esporte nos planos de governo. Confirmando assim, seu espaço incipiente na agenda das propostas dos candidatos ao Poder Executivo. Quanto ao Legislativo, funciona muitas vezes como plataforma eleitoral de militantes do campo, sem uma orientação central na busca por objetivos claros. Uma vez implementada, as políticas esportivas apresentam casos comumente "pautados por articulações político-econômico-sociais em defesa de interesses de grupos específicos, não necessariamente atendendo as demandas da sociedade em geral" (CANAN, 2019, p. 6). O autor ratifica uma questão referente à falta de robustez normativa que apresente premissas e diretrizes claras para a formulação e a implementação das políticas públicas no setor. "Tratam-se, no máximo, de influências às políticas de governo, encontrando-se ainda mais distantes das políticas de Estado" (CANAN, 2019, p. 6-7).

Nesse sentido, o livro aponta que está no âmbito do Executivo, a possibilidade de um maior direcionamento estrutural para a implementação das políticas de esporte no país. Sendo assim, os autores se debruçaram sobre os planos de governo de todas as candidaturas cadastradas no Tribunal Superior Eleitoral (TSE), aos cargos de Presidente da República e de Governador, dos 26 estados brasileiros e do Distrito Federal. O objetivo era identificar as propostas para o setor esportivo, ou relacionadas em alguma medida ao esporte, nas eleições de 2018. Em sequência, o autor diz: "Esperase com esse esforço de identificação e compilação de propostas relacionadas ao esporte informar todos os agentes relacionados ao campo esportivo e à sociedade em geral" (CANAN, 2019, p. 7).

No segundo Capítulo - Procedimentos Metodológicos - Canan nos apresenta: as características do estudo; e os meios utilizados para que o objetivo almejado fosse alcançado. "A pesquisa apresenta caráter descritivo e propõe-se à compilação das propostas relacionadas à área do esporte feitas pelas candidaturas" (CANAN, 2019, p. 7). Como já destacado, diferentes pesquisadores ficaram responsáveis pelo acesso à página eletrônica do TSE. A tarefa era identificar nos documentos oficiais, descritores relacionados ao campo esportivo.

Compuseram a amostra 13 (6,4\%) candidaturas à Presidência da República, 179 (88,18\%) aos Governos dos estados e 11 (4,49\%) ao Governo do Distrito Federal (DF), em um total de 203 (100\%). Destes, somente 7,39\% não tinham a proposta de governo cadastrada no TSE e 20,2\% não abordavam 
o esporte ou temas correlatos. A coleta foi realizada até o dia 19 de outubro de 2018. Além do foco sobre as propostas, os pesquisadores identificaram informações como: partido; coligação; nome do vice; cor/raça; gênero; idade; grau de instrução; e ocupação. Esses dados foram tabulados e apresentados por meio de gráficos analíticos, contudo, apenas no pleito do Governo Federal.

Quanto aos dados relativos às propostas, foi utilizado o descritor "esport", sem a letra "e" ao final, de forma a abranger as palavras: "esporte"; "esportiva"; "esportivo"; "desportiva"; "desportivo"; e "desporto". Todas no singular e no plural. Como há a compreensão, por parte dos autores do livro, de que o fenômeno esportivo é ampliado, assim como seus nomes e termos, foram então utilizados outros descritores como: "educação f"; "atividade f"; "atividades f"; "exercício f"; e “exercícios f". O intuito era incluir possíveis propostas relativas à educação física, atividade física ou exercício físico que eventualmente não se encontravam no descritor "esport".

Porém, essa expansão do olhar sobre as propostas ficou restrita também à disputa pelo Presidências da República. A justificativa se deu da seguinte forma: "Como a quantidade de casos em que os demais termos já não se encontravam abarcados na busca pelo descritor 'esport' foi insignificante, optou-se por descartar este tipo de busca em relação às propostas para Governo dos estados e do Distrito Federal"' (CANAN, 2019, p. 10).

Ainda no Capítulo 2, Canan aponta que para a apresentação dos dados procurou-se manter o padrão original de cada proposta e que em caso de dúvidas, as informações estariam disponíveis em: http://divulgacandcontas.tse.jus.br/divulga/\#/. Na sequência, o autor também afirma que não haveria nenhuma análise quanto ao conteúdo dos dados.

Nenhuma análise sobre as propostas relativas ao esporte e propostas de governo em geral foi tecida. Buscou-se com isso manter-se um caráter neutro, sem qualquer tipo de posicionamento político-partidário ou juízo de valor. Trata-se de um conteúdo meramente descritivo e informativo a fim de contribuir para o conhecimento de leitores, pesquisadores e agentes políticos em relação às propostas eleitorais para área do esporte (CANAN, 2019, p. 11).

Assim, ficou explícita a decisão dos autores de não aprofundamento no conteúdo pesquisado. Com uma exceção, não ao material das propostas em si: “o único procedimento de análise realizado foi um levantamento demográfico geral do perfil dos candidatos ao Governo Federal, levando em conta os indicadores etários, de gênero, raça/cor e ocupação" (CANAN, 2019, p11).

No terceiro Capítulo, Malagutti e Canan (2019) expõem quatro Figuras que representam gráficos analíticos a respeito do perfil dos 13 candidatos à Presidência (idade; gênero; cor/raça; e profissão). Segundo os dados coletados, oito postulantes possuíam mais de 60 anos; 11 eram do gênero masculino; 10 se autodeclararam brancos; e o gráfico com as profissões demonstrou uma 
grande variação quanto à ocupação laboral. Destacamos que as duas mulheres se autodeclararam da cor preta.

Na sequência, inicia a apresentação dos planos de governo e as respectivas propostas para o esporte. Este é o ponto forte do livro, quando o leitor se depara com as intensões de cada candidato em relação às políticas públicas de esporte. É um conteúdo denso com 190 páginas, somados Presidência e Governadores. Os autores foram assertivos em não excluir aqueles que não propuseram nada no plano de Governo relacionado ao objeto em questão. No local há escrito: “A proposta de Programa de Governo não faz qualquer menção ao esporte ou temas correlatos".

\section{APONTAMENTOS CRÍTICOS}

O material apresentado no livro possui relevância, pois traz luz à agenda da política esportiva no núcleo dos partidos políticos, afinal, um Programa de Governo extrapola o entendimento do assunto pela pessoa do candidato. Ou seja, o texto expõe a visão das respectivas chapas partidárias sobre o setor em questão.

Em uma análise mais crítica da obra apresentada, foi possível identificar alguns detalhes que merecem ser considerados, e que serão aqui elucidados. No início do livro, os autores afirmam que há, no Brasil, uma histórica aproximação das políticas de esporte com a manifestação esportiva de rendimento. Contudo, acreditamos que para fortalecer tal afirmação, seria interessante a apresentação de alguns dados que reforçassem esta hegemonia do desporto de rendimento. Talvez citações de estudos anteriores com indicadores já pesquisados poderiam enriquecer o argumento, evitando o risco de cair em um senso comum.

Em sua Tese de Doutorado, Bueno (2008) investigou razões para o predomínio do alto rendimento nas políticas de esporte no Brasil. Uma das suas contribuições foi a respeito das coalizões pró manifestações esportivas (rendimento; educacional; e participação) e suas proporções de representação junto ao órgão máximo de aconselhamento político, atualmente, o Conselho Nacional do Esporte ${ }^{1}$. Na tabela 1 é possível notar a distribuição desigual entre as categorias, mesmo após preceitos de valorização do desporto educacional e participativo, principalmente o primeiro, na Constituição Federal de 1988.

\footnotetext{
${ }^{1}$ O Conselho Nacional do Esporte é um colegiado de assessoria ao Ministro da Cidadania no desenvolvimento de políticas em prol do desporto nacional, representando um passo a mais na criação de novas perspectivas para o futuro do esporte no país. Criado pelo Decreto 4.201, de 18 de abril de 2002, o CNE tem por objetivo buscar o desenvolvimento de programas que promovam a prática intensiva e planejada da atividade física para toda a população, além da melhoria do padrão de organização, gestão, qualidade e transparência do setor (MINISTÉRIO DA CIDADANIA, 2021).
} 
Tabela 1 - Evolução da representatividade no órgão superior de aconselhamento

MANIFESTAÇÕES ESPORTIVAS

\begin{tabular}{lcccc} 
ANOS & Rendimento & Educacional & Participativo & Imponderável \\
\cline { 2 - 5 } & & & & \\
\hline 1993 & $73,30 \%$ & $0,00 \%$ & $0,00 \%$ & $26,70 \%$ \\
1998 & $30,00 \%$ & $0,00 \%$ & $0,00 \%$ & $70,00 \%$ \\
2000 & $40,00 \%$ & $13,30 \%$ & $13,30 \%$ & $33,30 \%$ \\
2002 & $52,90 \%$ & $5,90 \%$ & $0,00 \%$ & $47,10 \%$ \\
2003 & $63,60 \%$ & $4,50 \%$ & $9,10 \%$ & $22,70 \%$ \\
\hline
\end{tabular}

Fonte: Bueno (2008)

Outro campo de análise que dialogaria com a afirmação feita pelos autores do livro são os recursos investidos em cada perfil de desporto. O financiamento foi objeto de estudo de Carneiro e Mascarenhas (2018), no qual identificaram, dentre outros achados, o direcionamento do gasto com esporte no Governo Federal, no período de 2004 a 2015. O artigo apresentou a seguinte ordem decrescente: "esporte de alto rendimento" (25,08\%); "esporte, educação, lazer e inclusão social" (23,51\%); "infraestrutura" (21,94\%); "grandes eventos" (21,56\%); e "gestão" (7,91\%).

Carneiro e Mascarenhas (2018) destacaram que, em relação ao gasto em "infraestrutura", a grande maioria ( $\mathrm{R}$ \$ 6,43 bilhões de $\mathrm{R} \$ 6,52$ bilhões) do investimento foi destinada às ações finalísticas da categoria "esporte, educação, lazer e inclusão social". Por outro lado, "grandes eventos" representam a organização e realização de cinco competições do alto rendimento realizadas em um período de nove anos, sendo elas: Pan Rio 2007; Jogos Mundiais Militares 2011; Copa das Confederações FIFA 2013; Copa do Mundo FIFA 2014; e Jogos Rio 2016. Nesse sentido, tal estudo identificou uma distribuição próxima entre as categorias analíticas, demonstrando que em determinados períodos da política nacional esportiva, houve uma atenção relevante ao desporto educacional e participativo, ainda que o alto rendimento, alavancado pelo recebimento dos grandes eventos tenha sido o destino de um volume maior de recursos financeiros.

Quanto à metodologia utilizada, os autores decidiram não utilizar o mesmo grupo de descritores no conteúdo das propostas para Presidente e para Governadores. A justificativa utilizada foi a baixa prevalência dos termos alternativos a "esport", os quais eram: "educação f", "atividade f", “atividades f”, “exercício f” e “exercícios f”. Entendemos que, neste ponto, a explicação se mostra frágil e se limita ao peso da hipótese. O próprio livro destaca a complexidade do esporte como fenômeno amplo ligado à atividade física em geral e às diversas possibilidades de práticas corporais, assim como a capacidade de penetrar em diferentes políticas sociais dos mais diversos setores. A condicionante de exclusão dos outros descritores por pouco uso destes nas propostas a nível Federal, atua no sentido de homogeneizar o entendimento e o conceito do fenômeno esportivo no Brasil. 
Acreditar na replicabilidade deste ocorrido, junto às propostas dos candidatos a Governador, exclui o fato do objeto em questão ainda ser muito incipiente na agenda da políticas públicas, além de não considerar o pressuposto de estar pesquisando dados referentes a todo o país, ou seja, candidatos dos mais diversos contextos sociais e culturais e que podem refletir diretamente na construção textual das propostas, tal como no uso dos termos e conceitos. Compreendemos que seria válido manter o método de busca, com os mesmos descritores utilizados para o cargo de Presidente da República.

No Capítulo 3, as informações apresentadas pelas figuras ratificam a pouca representatividade de mulheres e pessoas negras nos pleitos eleitorais para o cargo máximo do Poder Executivo nacional. No entanto, a limitação do universo de presidenciáveis da eleição de 2018 restringe a análise. Certamente, se o livro demonstrasse estes indicadores relacionados aos estados e DF, enriqueceria mais o conteúdo, afinal, seria um $\mathrm{N}$ de 203 indivíduos e não somente 13.

A leitura do livro certamente nos instiga a inúmeras possibilidades de análise. De todo modo, preservando o intuito original de não auferir valor individual aos Planos de Governo, finalizamos esta resenha com alguns exemplos que poderão servir como forma de encaminhamento para ações futuras. Em uma perspectiva quantitativa, seria possível analisar quantos candidatos propuseram o esporte como atividade fim, coordenado por uma pasta que representasse o setor. Assim como, quantos como atividade meio, indicando a penetração da prática esportiva em outras políticas sociais. As áreas correlatas poderiam ser categorizadas, gerando dados interessantes, como por exemplo, a inserção do esporte nas propostas de saúde; educação; lazer; segurança pública; e trabalho.

Por fim, entendemos que "O esporte nas eleições 2018: candidaturas à presidência da república e aos governos dos estados" cumpre o papel de chamar atenção para um documento que auxilia a compreensão das políticas públicas em esporte no país. Contudo, acreditamos que, devido ao grande número de pesquisadores e grupos de pesquisa envolvidos, mesmo sem adentrar no mérito das propostas, algumas análises poderiam ter sido feitas, de modo que enriquecesse ainda mais o conteúdo do livro. A luz sobre estas, e futuras propostas de governo, pode nos oferecer indícios de como o esporte é pensado e absorvido pelos diferentes espectros do campo político-burocrático brasileiro.

\section{REFERÊNCIAS}

BUENO, Luciano. Políticas públicas do esporte no Brasil: razões para o predomínio do alto rendimento. 2008. Tese (Doutorado em Administração Pública e Governo) - Escola de Administração de Empresas de São Paulo da Fundação Getúlio Vargas, São Paulo, 2008. 
CANAN, Felipe. Introdução. In: CANAN, Felipe; STAREPRAVO, Fernando Augusto; SILVA Temistocles Damasceno. (orgs.). O esporte nas eleições 2018: candidaturas à presidência da república e aos governos dos estados. 1 ed. Marechal Cândido Rondon: UNIOESTE, 2019. p. 5-7. Disponível em:

https://www.researchgate.net/publication/333118874 O ESPORTE NAS ELEICOES 2018 Acesso em: 01 nov. 2020.

CANAN, Felipe. Procedimentos Metodológicos. In: CANAN, Felipe; STAREPRAVO, Fernando Augusto; SILVA Temistocles Damasceno. (orgs.). O esporte nas eleições 2018: candidaturas à presidência da república e aos governos dos estados. 1 ed. Marechal Cândido Rondon: UNIOESTE, 2019. p. 5-7.

Disponível em:

https://www.researchgate.net/publication/333118874_O_ESPORTE_NAS_ELEICOES_2018 Acesso em: 01 nov. 2020.

CARNEIRO, Fernando Henrique Silva; MASCARENHAS, Fernando. O FINANCIAMENTO ESPORTIVO BRASILEIRO: proposta de metodologia crítica de análise / sports financing in brazil. E-Legis - Revista Eletrônica do Programa de Pós-Graduação da Câmara dos Deputados, [S.L.], v. 11, p. 119-140, 6 nov. 2018. Camara dos Deputados. http://dx.doi.org/10.51206/e-legis.v11i0.481.

MALAGUTTI, João Paulo Melleiro; CANAN, Felipe. Brasil. In: CANAN, Felipe; STAREPRAVO, Fernando Augusto; SILVA Temistocles Damasceno. (orgs.). O esporte nas eleições 2018: candidaturas à presidência da república e aos governos dos estados. 1 ed. Marechal Cândido Rondon: UNIOESTE, 2019. p. 5-7. Disponível em:

https://www.researchgate.net/publication/333118874_O_ESPORTE_NAS_ELEICOES_2018 Acesso em: 01 nov. 2020.

\section{NOTAS DE AUTOR}

\section{AGRADECIMENTOS}

Agradecemos ao corpo docente e discente da disciplina de Políticas Públicas de Esporte e Lazer do Programa de Pós-Graduação em Educação Física da Universidade Estadual de Maringá.

CONTRIBUIÇÃO DE AUTORIA - Não se aplica

FINANCIAMENTO - Não se aplica.

CONSENTIMENTO DE USO DE IMAGEM - Não se aplica.

APROVAÇÃO DE COMITÊ DE ÉTICA EM PESQUISA - Não se aplica.

CONFLITO DE INTERESSES - Não se aplica.

\section{LICENÇA DE USO}

Os autores cedem à Motrivivência - ISSN 2175-8042 os direitos exclusivos de primeira publicação, com o trabalho simultaneamente licenciado sob a Licença Creative Commons Attribution NonComercial ShareAlike (CC BY-NC SA) 4.0 International. Esta licença permite que terceiros remixem, adaptem e criem a partir do trabalho publicado, desde que para fins não comerciais, atribuindo o devido crédito de autoria e publicação inicial neste periódico desde que adotem a mesma licença, compartilhar igual. Os autores têm autorização para assumir contratos adicionais separadamente, para distribuição não exclusiva da versão do trabalho publicada neste periódico (ex.: publicar em repositório institucional, em site pessoal, publicar uma tradução, ou como capítulo de 
livro), com reconhecimento de autoria e publicação inicial neste periódico, desde que para fins não comerciais e compartilhar com a mesma licença.

\section{PUBLISHER}

Universidade Federal de Santa Catarina. Programa de Pós-Graduação em Educação Física. LaboMídia - Laboratório e Observatório da Mídia Esportiva. Publicado no Portal de Periódicos UFSC. As ideias expressadas neste artigo são de responsabilidade de seus autores, não representando, necessariamente, a opinião dos editores ou da universidade.

\section{EDITORES}

Mauricio Roberto da Silva, Giovani De Lorenzi Pires, Rogério Santos Pereira.

\section{EDITOR DE SEÇÃO}

Silvan Menezes dos Santos

\section{REVISÃO DO MANUSCRITO E METADADOS}

João Caetano Prates Rocha; Keli Barreto Santos, Juliana Rosário.

\section{HISTÓRICO}

Recebido em: 26 de maio de 2021.

Aprovado em: 13 de setembro 2021. 